Part I

Historical 


\title{
Amateur Astronomy from Its Origins to Camille Flammarion
}

\author{
Jean Seidengart \\ Université de Paris X, 2 rue de Rouen, F-92001 Nanterre Cedex, France
}

\section{Introduction}

It is not possible to sketch the history of astronomy by amateurs without first defining what the term "amateur astronomer" truly means. But we must avoid using "the benefit of hind-sight" to interpret the past in terms of a concept, the relevance of which has been perceived only during the course of the last one hundred years. In order to avoid the sophistry arising from such a purely imaginary history that is based on false conceptions, it is useful to examine amateur astronomy's precise status, since its emergence in the dawn of classical science, by outlining the type of relationship that it has had with "professional" astronomy. In doing so, we can evoke some of the major developments in amateur astronomy, the scientific contributions of which, although often of high quality, have at times reached the very forefront of the discipline of astronomy.

In early classical French, the term "amateur" referred to anyone who had a keen interest in the arts, being based primarily on the strong love that could arise for any object capable of stirring the emotion. In the course of the 17 th century, the term came to be extended to cover the sciences and other fields in general. An amateur is therefore, above all, anyone who does not live by astronomy - disregarding how meagre the income of official astronomers may have been in the past. From this we may see that it has to be one thing or the other: either amateurs gain their income from some other professional activity - but they are then unable to devote their whole time to astronomy - or else they are sufficiently rich to be able to give their undivided attention to their love. In the latter case, however, they risk being just a "dilettante" (that is to say no more than a "curiosity-seeker", who is only drawn by what is unusual or new); a dilettante, moreover, whose practice of astronomy is influenced more by inclination than by the exigencies of a plan of research that has been methodically and rationally devised within an overall cooperative programme. Dilettantes are not forced to preserve any continuity in their observational programmes, the content of which may vary according to the whim of the moment.

Amateurs, therefore, have less time at their disposal than professionals, or else work in a very disjointed fashion. In most cases their initial theoretical grounding is much shallower and less technical than that of professionals, even if these same amateurs have often been professional scientists in other disciplines (mathematics, 
mechanics, optics, engineering science, etc.). With some rare exceptions (some of which have been of the greatest importance as we shall see in considering Herschel and Lord Rosse), amateurs have only modest technical and material resources at their disposal, and these are also frequently of poorer performance than those of professionals, especially from the 19th century onwards. Nevertheless, if we leave aside the casual "curiosity-seekers" and the "dilettantes", we are still left with the "experts", who have been capable of making skilled observations that are not only regular, but also are precise in their measurements. As we shall see, the development of astronomy owes much to them and this because, in the words of Alexander Koyré, they have been able to rise from "the world of the approximate to the Universe of the precise". Advanced amateurs, in the true sense of the term, are therefore those who have been able to go beyond the charms of simply contemplating the splendour of the heavens - which, nonetheless, remains irreplaceable - and to venture farther along the path of knowledge. Eudoxos' teacher, Plato, writing in his Timaeus, warned the merely curious that:

"They came from harmless but light-witted men, who studied the heavens but imagined in their simplicity that the surest evidence in these matters comes through the eyes." (1)

It is not possible, of course, within the limits of this paper, to review exhaustively the work of amateurs between the Renaissance and modern times. To the best of our knowledge this research has never been fully undertaken, and indeed could not be carried out in any truly significant manner, because, until the end of the 18th century, the strict distinction between very advanced amateurs and officially appointed professionals hardly had any historical or epistemological relevance. Indeed, from the end of the Middle Ages until the creation of the various academies and learned societies during the classical age, it was just as likely for an "official astronomer" - the term "mathematicus" was often used - to have been a charlatan, preoccupied with astrology, or even someone more concerned with intrigue and avid for power or political influence, as for them to be a professional or a well-informed amateur. It is true that in Europe astrology was often part of the official functions of a court astronomer until the middle of the 17th century: Kepler was one of the last astronomer-astrologers of the court at Prague.

In this respect, it must be recognized that the foundation throughout Europe, during the 17th and 18th centuries, of academies and societies that could carry out collective research, did at least improve the situation to some extent. By giving an institutional status to scientific disciplines it became possible to organize and coordinate research, and to supervise the quality and level of publications. At the end of the 18 th century, astronomy's autonomy was finally recognized and, as D'Alembert notes fifty years later in the Encyclopédie:

"Today there are only astronomers, and no astrologers, or at least astrologers are held in very low esteem." (2)

In order to avoid any confusion over classification, we shall only begin our discussion of amateur astronomy with the scientific revolution of the 16th and 17th 
centuries, even though astronomy is a very much older science, and was practiced by many renowned scientists in antiquity from the time of Eudoxos to that of Ptolemy. Our treatment is determined by the amateur/professional dichotomy, the pertinence of which only appeared with the institutionalization of science in accordance with internal criteria of scientific competence. We shall see in the historical outline that follows that these general considerations of amateurs' contributions to the development of astronomy fall into four distinct, yet often interdependent, fields: observation, instrumentation, theory and, on the educational side, the global dissemination of astronomical knowledge.

\section{The Dawn of the Scientific Age}

With the dawn of the scientific age, the very small number of professional astronomers, whose status was still not properly defined, did have the effect of creating a considerable extension to the concept of amateur astronomy. The first "expert amateurs" at that time were specialists in other scientific disciplines (mathematicians, physicists, engineers, navigators, geographers, etc....), philosophers preoccupied with the question of knowledge and natural philosophy, teachers at the religious and royal colleges who often taught several disciplines at once, and self-taught men drawn from various social and professional backgrounds (artisans, business-men, military officers, clerics, aristocrats, land-owners, etc....). Let us note in passing that the passion for astronomy encouraged international exchange of ideas and overcame the social barriers found under the Ancien Regime, with a few isolated exceptions.

While Peiresc and Gaultier only just failed to observe the transit of Mercury across the disk of the Sun that had been predicted by Kepler, Gassendi was the only person to observe it, which he did and with precision, on 1631 November 7 from Paris. Moreover, he gave a full description in his paper of 1632, Mercurius in sole visus. Kepler's prediction thus had brilliant, and important, observational confirmation.

After the death of Peiresc in 1637, Gassendi continued to make observations, which can be found in volume IV of the latter's Oeuvres Complètes, but there is no really notable discovery amongst them. He did have the distinction of refuting the error made by Father Rheita, who thought he had discovered five new satellites of Jupiter. One remarkable result of the cooperation between these two great amateurs that is still remembered, however, is the very first map of the Moon, which they had engraved by Mellan in 1636. D'Alembert praises it a century later in the Encyclopédie:

"Of all the maps of the Moon that have been published up to the present, those that were engraved by Mellan, under the supervision of Peiresc from the observations of Gassendi, are without doubt the best, and the most representative." (3)

During the same period, Father Niccolo Zucchi, S.J. (1586-1670), built, in 1616 , one of the very first telescopes making use of an ocular to observe the image 
produced at the focus of a concave metal mirror. With this apparatus, Niccolo Zucchi observed, in 1640, the markings discovered on Mars by Fontana in 1636, and he went on to discover the existence of belts on Jupiter.

Another notable person is Fontenelle (1667-1757). This time, we are dealing with a writer devoted to the dissemination of the ideas and discoveries of the "Progressives". In this respect, the Entretiens sur la pluralite des Mondes (1686) represents a deliberate attempt to render the achievements of "Copernican" astronomy accessible to everyone. Even if Fontenelle had recourse to literary devices to present the material in a light-hearted manner, he still remained faithful to Cartesian epistemology. Fontenelle shows his reader that the drama of the universe should inspire us to enquire into the fundamental mechanisms that produce the successive scenes on stage. It is all as if the new, Copernican astronomy of Kepler and Galileo had taken us behind the scenes, and this knowledge increases the value of the very drama itself:

"There is nothing that should interest us more", says Fontenelle, "than to know how this world that we inhabit is made, whether there are other similar worlds, and if they also are inhabited." (4)

The book was aimed at the widest possible audience, because, according to its author, it was capable of pleasing both the reader with a knowledge of physics, and the beginner:

"I must advise those who will read this book, and who have some knowledge of physics, that I have not presumed to try to give them instruction, but rather to divert them in presenting, in a perhaps more pleasant and lighter fashion, that which they already know. To those for whom this material is new, I would say that I have tried to instruct and to amuse them at the same time. The former will be going against my intentions if they look for instruction in this book, and the latter if they only look for amusement." (5)

As far as science was concerned, Fontenelle was only an amateur, albeit wellinformed in mathematics by his friend the great geometer Sauveur, in astronomy by La Hire, and in physics by Christiaan Huygens. The various successive editions of the Entretiens revised by Fontenelle incorporate all the new discoveries made after 1686, up to the edition of 1742 , which is by far the most complete, because it adds a "sixth day", which has as a sub-title: "New thoughts that confirm the preceding discussions. The latest discoveries that have been made in the heavens." (6) The work spread across Europe like a trail of gunpowder, and brought fame to its author, who thus began a new literary genre: that of scientific popularization.

In his Kosmotheoros of 1698 - as famous throughout Europe at the time as Fontenelle's Entretiens - Huygens described the astronomical knowledge of that period, as well as his own discoveries. Huygens represents another type of amateur, quite different from Fontenelle. He was a great Dutch scientist, who worked for nearly twenty years at the Académie Royale des Sciences in Paris. He made discoveries in most of the branches of the physical and mathematical sciences, but he did 
not pretend to be a professional astronomer of the type represented by Hevelius, La Hire or Jean-Dominique Cassini. In astronomy for example, with his brother Constantijn he constructed refractors of very great focal length $(3.5 \mathrm{~m}$ and $7 \mathrm{~m})$ in order to avoid spherical and chromatic aberration; these had magnifications of $\times 100$ times. Using one of his telescopes he discovered Titan, the largest satellite of Saturn, in March 1655. Then he solved the problem about the shape of Saturn, raised by Galileo in his Siderius Nuncius. Huygens discovered the ring surrounding the planet during the winter of 1655-1656, at a time when the "ansae" were invisible. He did not publish his discoveries until 1659, in his Systema Saturnium. On the instrumental side, in order to increase the field of his powerful telescopes, Huygens had the idea of placing a field lens in front of the eye lens, which on the one hand created a new type of ocular - still used nowadays and well-known to amateurs and on the other eliminated chromatic aberration. This made it possible to increase the focal length of his refractors (going from $7 \mathrm{~m}$ to 15 , and then to 30 and $60 \mathrm{~m}$ !) and thus their magnification, whilst still preserving a useful field, providing tubes, with their incurable flexure, were abandoned.

In his Kosmotheoros, published posthumously, Huygens described a finding that was very remarkable for its time. Suggesting that all the visible stars had approximately the same dimensions, he argued that the differences in their visual magnitudes were a function of their distance from the terrestrial observer. As Sirius had the greatest visual magnitude, he attributed its brightness, not to its actual diameter, but to the fact that it was very close to the Solar System. Pointing his telescope at the Sun, after having stopped it down by capping it with a sheet of metal through which a small hole allowed the Sun's light to pass, he blocked the hole in its turn with a bead of glass, thus reproducing the appearance of Sirius. Huygens argued that Sirius actually had the same diameter as the Sun, but that their difference in brightness was because of the extreme distance of the principal star in Canis Major. He concluded:

"Thus, making the calculations according to the laws of dioptrics, I found that the diameter of the Sun had become 1/152 part of the fraction of $1 / 182$ that I saw the first time through the small hole. The product of $1 / 152$ and $1 / 182$ is $1 / 27664$. As a result, if we assume that Sirius is equal to the Sun, it follows that the ratio of its distance to that which separates us from the Sun is 26664 to $1 .$, (7)

Huygens thus anticipated the photometric method by two centuries, and even though the postulate that all stars have the same diameter was false, he nevertheless had the distinction of giving stellar distances that were an order of magnitude better than those put forward by Kepler, who spoke of 600000 Earth diameters. Huygens' figure, although less than the actual one, was 538 times better than Kepler's. His value was given by Fontenelle in his Entretiens from 1708 onwards, and it can still be found up to the beginning of the 19 th century! 


\section{The Eighteenth and Nineteenth Centuries}

In the 18th century, Newtonian theories reached their height, and were finally accepted throughout Europe, even by the most reluctant spirits. Amateur astronomy had spread considerably among the various classes of western society (to which we restrict ourselves). Numerous well-informed amateurs were members of regional scientific societies, and even of the leading national institutions. For example, as Lesley Murdin has shown so clearly in her recent work on astronomical practice in the classical age (8), there were so many amateurs in England at the end of the 17 th century that they were the subject of famous satires and lampoons at the time. Whether these amateur astronomers were of private means like Molyneux, or clergymen like William Derham and James Pound, there were more than fifty of them who sent regular communications and observations to John Flamsteed, the famous Astronomer Royal at Greenwich. In France at the beginning of the 18th century, observatories, and on a more modest scale, private observing sites, were increasing. Bigourdan, in this work (9), lists a score in the region around Paris, half of which belonged to individuals. In the provinces, the observatories belonged to educational institutions, local academies, or to individuals. There were purely private observatories or serious observing sites at Toulouse, Avignon, Marseille, Lyon, Montpellier, Mirepoix, Béziers, Saint-Lô, Viviers, Bordeaux, Montauban, Bourg-en-Bresse, etc. In astronomy it is indeed very useful to have a number of observers situated in different geographical locations well separated from one another, but it is nevertheless necessary for their observations to be coordinated and integrated within specific, methodically organized, research programmes. It was just this organization of research that was missing at that time in astronomy. In France it had to await the creation of the Bureau des Longitudes in 1795, for astronomical research to be organized and centralized, not to speak of the quite indispensable metrological reforms that were carried out by the Commission des poids et mesures under the Constituent Assembly.

Amongst all the amateur astronomers of the 18th century, one great figure stands out in the person of William Herschel (1738-1822), whose expertise and rigorous methods put him on a par with professionals. Originally a musician (he was an oboeist in the Hanoverian royal army), William Herschel emigrated to England where he developed a passionate interest in astronomy. The poor quality of telescopes that he had bought second-hand encouraged him to grind and polish mirrors himself. In 1782 he managed to complete mirrors that were far superior to those used by the official astronomers. The latter soon recognized his exceptional gift for manufacturing optical instruments and officially congratulated him about it. With one of his favourite instruments, Herschel discovered in 1781 a trans-Saturnian planet (which he took initially to be a comet), and which his friend the German astronomer J.E. Bode later called Uranus. This launched him on his true career, and he undertook the preparation of a catalogue of double stars that ended by including 848 pairs. He tried to construct a telescope 3 feet in diameter $(91.44 \mathrm{~cm})$ and more than $9 \mathrm{~m}$ long, but the mirror fractured on cooling. In 1789 he constructed, in what was an unimaginable feat at that time, a giant telescope, $1.22 \mathrm{~m}$ in diameter and more than $12 \mathrm{~m}$ long! Handling this telescope was rather difficult, but as soon as he put it into service he discovered the sixth satellite of Saturn. However, the Solar System 
did not interest him as much as the structure of the universe, to the study of which he devoted the rest of his life. In this respect, Herschel is the founder of modern observational cosmology.

As far as theoretical cosmology was concerned, the 18 th century saw an amateur of genius, originally a philosopher, in Immanuel Kant. In 1755 the young Kant published his Universal Natural History and Theory of the Heavens, where the first correct conception of the structure of our Galaxy appeared, as well as the outline of what was later to be called the theory of "island-universes" (10). But Kant's hypothesis, correct though it was, remained entirely speculative and without a sufficient observational basis. It was this gap that Herschel undertook to fill, with the help of his giant telescope, the most powerful one in the world at that time. The famous astronomer Messier had, of course, already published a catalogue in 1781 that included about one hundred celestial objects that were nebular in appearance. For his part, Herschel, after twenty years of painstaking observation, described more than 2500 "nebulae" in his new catalogue of 1802 . The decisive question was to determine the nature of these "nebulae". Were they clouds of dust and gas illuminated by nearby stars, or were they luminous in their own right? In other words were they not rather quite extensive clusters of stars? In the latter case, were these clusters of stars part of our Galaxy, or were they "extragalactic" in nature?

During the $1780 \mathrm{~s}$, Herschel put forward the view in numerous, important communications to the Royal Society, that all the "nebulae" must in fact be stellar clusters capable of being resolved into stars, with the exception of those that were too distant for the observational means available at that time. Herschel was to revise, and even totally change his opinion about the nebulae, when in November 1790 he discovered a nebula that consisted of a central star surrounded by a cloud of gas, and which is traditionally (but incorrectly) called a "planetary nebula" (11). He ended up by recognizing that this nebula is nearby and that its nebulosity could not be resolved into stars. It was equally the cause of his revising his cosmological ideas, which had a considerable influence on Laplace. Only in 1811 did W. Herschel describe to the Royal Society his evolutionary theories on cosmological subjects, in a paper of primary importance (12). He saw the nebulae as being a primitive stage in the formation of stars, which arose from a condensation of the nebular material under the force of gravity alone. The astronomer P.S. de Laplace, when he heard of Herschel's paper, saw in it obvious observational confirmation of his own cosmological theories, developed since 1796 in the various successive editions of his Exposition du systeme du monde. Laplace states in the 1813 edition of the Exposition:

"The nebulae classified according to this philosophical scheme of Herschel's indicate that there is a considerable likelihood of their being transformed, at some future date, into stars. (...) Such a remarkable agreement, arrived at by following completely different routes, means that the existence of this earlier state of the Sun is very probably the truth." (13)

During the twenty years that followed the publication of his research about the nebulae, W. Herschel, who had been aided by his sister Caroline, was showered with honours by the king, George III, who appointed him astronomer to the royal 
family and gave him an annual pension of 200 pounds. Herschel is therefore one of the group of amateurs who became professionals.

To conclude this outline, which is really too short and too selective for such a subject, we should not fail to mention the remarkable case of William Parsons, the third Lord Rosse (1800-1867). With him we have reached the middle of the 19th century, at a time when the professional astronomers mainly used refractors, the accuracy and reasonable focal lengths of which - by comparison with Herschel's "monsters" - gave better service by reason of their efficiency and ease of handling. After sound scientific studies at Oxford, the future Lord Rosse undertook the construction of a giant reflector, despite all the difficulties presented in perfecting a bronze mirror. He intended to exceed the dimensions of Herschel's reflector, which had a diameter of 4 feet $(1.22 \mathrm{~m})$, with a 6 -foot $(1.83 \mathrm{~m})$ reflector. Helped by a considerable fortune, he turned the family mansion at Birr Castle into a foundry and cast a 4-tonne mirror which took 16 weeks to cool. After some set-backs, he succeeded with his fifth mirror in April 1842. The focal length of the mirror was more than 16 metres, and after a difficult polishing process, he finally attained a resolving power of $1 / 10$ th of a second of arc, with a magnification of $\times 828$. Lord Rosse gave his "Leviathan" a filar micrometer with phosphorescent threads in order to be able to obtain precise measurements, whilst reaching magnitude 17 ! The gigantic monster outclassed every other instrument in the world, and became operational in 1845. Lord Rosse and his friend, the Reverend Thomas Romney Robinson observed from 1848 to 1878 , and carried out the first astronomical photography and spectroscopic studies. The results, although spectacular, did not bring all the advances that one might have expected. Lord Rosse did, however, succeed in determining the structure of the spiral arms of galaxies, notably in M 51, and also in resolving a large number of both globular and open clusters. But he was unable to resolve stars in galaxies and thus put a decisive end to the controversies that raged at the time about the nature of the nebulae. A definitive reply to this question did not come until 1924, when it was thanks to the remarkable observational work by E. Hubble (who was himself originally an amateur astronomer). Lord Rosse had not realised that it was not enough just to construct a giant telescope for it to give immediate results concomitant with its theoretical capacity, it needed to have an adequate site, with clear skies, which was certainly not possible on his small Irish estate. If for this reason Lord Rosse is not an incomparable observer, he is at least a highly ingenious inventor.

\section{Conclusion}

These various historical examples show us that the contribution of amateurs in the past is not really distinct from the rest of astronomy: indeed on several occasions it has been at the very forefront of research, in that heroic age when there were such pioneers. Then, in the second half of the 19th century, French amateur astronomers had the chance to join a society founded by Camille Flammarion: it was then that amateur astronomy in France achieved full status and entered a new phase, with the results that we see around us now. 


\section{References}

1. Plato, in Timaeus, 91 D-E, trans. Cornford, F.M., London, 1937; see also The Republic, Book VII, 529, A-C

2. D'Alembert, Encyclopédie, 1756, Tome 1, p.783

3. Op. cit., cf note 2

4. Fontenelle, Entretien sur la pluralité des Mondes, 1742 edn, preface

5. Fontenelle, ibid.

6. Fontenelle, op. cit., ed. Marabout, after edn of 1742, p.121

7. Christiaan Huygens, Kosmotheoros, sive De Terris Coelestibus, earumque ornatu, Conjecturae, den Haag, 1698. [2nd English-language edition: The Celestial Worlds Discovered..., London, 1722 - Eds.]

8. Lesley Murdin, Under Newton's Shadow, Bristol \& Boston, Adam Hilger, 1985

9. Bigourdan, Histoire de l' astronomie d'observation et des observatoires en France, Paris, 1930

10. Kant, Allgemeine Naturgeschichte und Theorie des Himmels, Königsberg \& Leipzig, 1755. [Universal Natural History and Theory of the Heavens, trans. Hasties, W., Univ. Michigan Press, Ann Arbor, 1969, or the same author's Kant's Cosmogony, London, 1900, - Eds.]

11. This "planetary nebula" is probably NGC 1514, magnitude 10.8 , situated at a distance of 4300 light-years; $\alpha 4^{h} 06.2^{m}, \delta+30^{\circ} 38^{\prime}$.

12. c.f. Philosophical Transactions, 1811, p.269 et seq.

13. Laplace, Exposition du système du monde, 4th edition, Paris, 1813, p.431. 